\title{
LOS SUPERMERCADOS Y CAMBIOS EN LA CADENA PRODUCTIVA PARA LA PAPA EN EL PERÚ
}

\author{
Shimizu, T. ${ }^{\text {; }}$ G. J. Scott ${ }^{2}$
}

\begin{abstract}
Resumen
Mientras la oferta y demanda de alimentos han crecido notablemente en el Perú en las últimas décadas, el sistema de comercialización tradicional está demorando en adaptarse a los cambios. La mayor parte de los productos hortícolas frescos que ingresan a Lima se distribuyen a través de los canales tradicionales. Sin embargo, en los últimos años el número de supermercados está aumentando no solamente en Lima sino también en las principales ciudades del país. Tomando la compra de papa por los supermercados en Lima como un caso, este estudio analiza cómo la comercialización de alimentos está en un proceso de transformación en el Perú. Los resultados del estudio muestran que los supermercados ya no se abastecen de papa en el mercado mayorista en una forma diaria sujeto a los precios y calidades de los tubérculos en venta, sino compran a los proveedores especializados en una forma coordinada y planeada para asegurar la calidad del producto y un abastecimiento continuo.
\end{abstract}

Palabras claves adicionales: Canales de comercialización, mercado mayorista, variedades.

Aceptado para publicación: 14 de febrero del, 2014

\footnotetext{
${ }^{1}$ Investigador, Institute of Developing Economies, Japan External Trade Organization (IDE-JETRO), E-mail: tatsuya_shimizu@ide.go.jp

${ }^{2}$ Profesor, CENTRUM Católica Graduate Business School, Pontificia Universidad Católica del Perú
} 


\title{
SUPERMARKETS AND CHANGES IN THE VALUE CHAIN FOR POTATO IN PERU
}

\begin{abstract}
Summary
While food supply and demand have expanded rapidly in recent decades in Peru, the marketing system is taking time to adapt to these changes. The bulk of all fresh fruits and vegetables entering Lima are still distributed through traditional marketing channels. However, in recent years, supermarket chains are expanding not only in Lima but also in major regional cities. Taking supermarket procurement of potatoes in Lima as an example, this study analyzes how food marketing practices are evolving in Peru. The study found that supermarkets have shifted their sourcing away from the traditional daily purchases in the central wholesale market subject to prevailing prices for the quality of tubers available for sale, closed and coordinated channels with specialized traders to ensure product quality and continuous supply.
\end{abstract}




\section{Introducción}

En muchos países en vías de desarrollo, las condiciones de demanda de los alimentos están cambiando rápidamente. El avance de la concentración de población en las ciudades principales, el incremento de los ingresos de sus pobladores a consecuencia del desarrollo económico, los cambios en sus dietas y hábitos de compra, son algunos ejemplos. Mientras los actores tradicionales de la cadena productiva de alimentos, tanto mayoristas como minoristas, están enfrentando nuevos retos para adaptarse a estos cambios, los nuevos actores tales como los supermercados se están expandiendo rápidamente ofreciendo los servicios que desean los consumidores (Tollens, 1997; Reardon et al., 2003; Reardon y Timmer, 2007). Especialmente en América Latina, la presencia de los supermercados es notable (Reardon y Berdegué, 2002). En algunos países, la participación de los supermercados superan el $50 \%$ de la venta de alimentos al por menor mientras que recién se está expandiendo en otros como el Perú ${ }^{3}$.

En el Perú la participación de los supermercados en las ventas generales al por menor se calculó en $15.6 \%$ en el 2011 , y en la venta de alimentos en Lima el mismo año se estimó en $35 \%$ (USDA, 2012). Sin embargo, su presencia está siendo cada vez mayor especialmente en la capital, el mercado más importante del país. Anteriormente los supermercados se encontraban en las zonas de Lima con mayor poder adquisitivo. Hoy en día están abriendo locales en las zonas populares, donde los ingresos de la población son relativamente menores, pero donde también se están alcanzando niveles cada vez más altos. El número de tiendas de las cadenas de supermercados en la capital llegó a 190 en el 2012 y se proyecta que habrá 350 en el mediano plazo (La República, 25 de diciembre de 2012). Adicionalmente, algunas cadenas de supermercados se están expandiendo activamente en las principales ciudades de la costa y sierra.

\footnotetext{
${ }^{3}$ Las cifras de la participación de supermercados en los países principales de América Latina se encuentran en los informes de cada país de "Retail Food Sector" de USDA Global Agricultural Information Network (http://gain.fas.usda.gov/).
} 
En el caso de los productos no alimentarios, los supermercados pueden comprar directamente a las empresas fabricantes, 0 procesadores, aprovechando las economías de escala. La calidad de los productos está garantizada por los fabricantes y procesadores. Sin embargo, en el caso de productos agrícolas como frutas y verduras frescas, la situación es diferente. No hay empresas grandes que puedan satisfacer la demanda de los supermercados y garantizar la calidad de sus productos salvo algunas empresas exportadoras en el caso de ciertas frutas y verduras específicas. Los mayoristas supuestamente tienen la función de ofrecer las cantidades de los productos que los supermercados demandan. No obstante, en Lima como en otros países en vía de desarrollo, los mayoristas tienen dificultades de cumplir esta función. Los estándares de clasificación pueden variar mucho según la estación con tendencias de mezclar productos de diferentes calidades y tamaños (Reardon y Berdegué, 2002: 380); la capacidad del sector público de hacer respetar las normas de calidad y de peso está limitada (Humphrey, 2007).

Para las cadenas de supermercados, un ancla clave de su modelo de negocio y su expansión está basada en una estrategia de ofrecer sus clientes productos hortícolas de alta calidad. Por otro lado, dada el crecimiento en el número de sus tiendas y las proyecciones sobre su futura expansión, los procedimientos y productos que ofrece el canal tradicional generan un desajuste entre la oferta de los mercados mayoristas y el tipo de producto demandado por las cadenas de supermercados. Como consecuencia, para abastecerse con los productos que ellos desean, los supermercados decidieron organizar sus propios canales de compra.

El objetivo de este estudio es analizar la transformación de la cadena productiva de alimentos tomando como ejemplo los canales de abastecimiento de papa de los supermercados en Lima. La papa es uno de los alimentos principales para los peruanos, y los supermercados son protagonistas importantes en la transformación de la comercialización de alimentos hoy en día. Han habido varios estudios sobre uno u otro aspecto de los cambios en la comercialización de la papa en el Perú (Scott, 
1985; Alarcón, 1994; Escobal, 2000; Alarcón y Ordinola, 2002; Bernet et al., 2002; Bernet et al., 2008; CEPES, 2010; Devaux et al., 2010; Meinzen-Dick et al., 2009; Proexpansión, 2011; Scott, 2011a, 2011b; Scott y Zelada, 2011; Escobal y Cavero, 2012; Horton y Samanamud, 2013). Sin embargo, ninguno de ellos ha analizado en detalle los cambios promovidos en la compra y venta de papa por los supermercados, y menos por qué los supermercados utilizan procedimientos diferentes a los practicados por los participantes en las cadenas tradicionales.

El resto del artículo se organiza en la siguiente manera. La segunda parte presenta los materiales y métodos, enfatizando la síntesis de datos secundarios e información primaria. La tercera parte presenta los resultados y su discusión, explicando a la vez los cambios en el sector de la papa durante las últimas décadas seguido de las características de la compra de papa adoptadas por los supermercados. En la conclusión, se presenta un repaso de los hallazgos principales y su importancia antes de señalar algunos temas para investigaciones futuras.

\section{Materiales y Métodos}

Este estudio está basado en cuatro componentes: una revisión de literatura; un análisis de datos secundarios sobre producción y consumo de papa a nivel nacional, y los flujos de papa hacia el mercado mayorista de Lima; entrevistas semi-estructuradas con informantes claves; y la observación participativa en diferentes puntos en la cadena de comercialización de la papa.

La revisión de la literatura se basa en dos tipos de estudios. El primero es la literatura sobre la modernización de la comercialización de alimentos en los países en vías de desarrollo, la difusión de los supermercados, y los factores detrás de estos cambios. El segundo trata de la evolución del sector de la papa en el Perú. En otras palabras, para contextualizar un análisis de las actividades de comercialización de papa hoy en día, se sintetizó los estudios y datos sobre los cambios en la oferta y demanda del cultivo en las últimas 
décadas y su impacto sobre los canales de comercialización.

El análisis de la compra de papa por los supermercado en si está basado en las entrevistas semi-estructuradas a las personas encargadas de la compra de hortalizas en los tres principales cadenas de supermercados en el Perú: Cencosud (tiendas Wong y Metro), Supermercados Peruanos (tiendas Plaza Vea y Vivanda) y Tottus (tiendas Tottus). También se entrevistaron a tres proveedores de papa que abastecen a estas cadenas. Además, el manejo post cosecha de la papa fue observado y estudiado en persona a través de visitas al Mercado Mayorista Central (MM\#1) en La Parada y el Gran Mercado Mayorista (GMM) en Santa Anita, los almacenes centrales y centros de acopio de los supermercados además de las instalaciones de sus proveedores. Estas entrevistas y observaciones fueron realizadas en Lima entre mayo y noviembre de 2012, seguida por visitas selectivas llevadas a cabo en Julio 2013 y en Enero 2014.

Este estudio analiza la transformación de la cadena productiva de papa utilizando el marco teórico del análisis de cadenas productivas. Analizamos la estructura de la cadena desde los productores hasta los consumidores. En el análisis se identifican los actores principales de la cadena; las funciones físicas y de coordinación que ellos cumplen; y las características de las relaciones entre actores y las transacciones entre ellos. También, se detectan los factores que determinan las estructuras de dicha cadena y los factores que influyen en los cambios de ella. El enfoque está en la coordinación vertical entre supermercados y proveedores, y las estrategias de abastecimiento de los supermercados (Humphrey, 2007: 442). 
Figura 1: Los canales de comercialización de papa para Lima

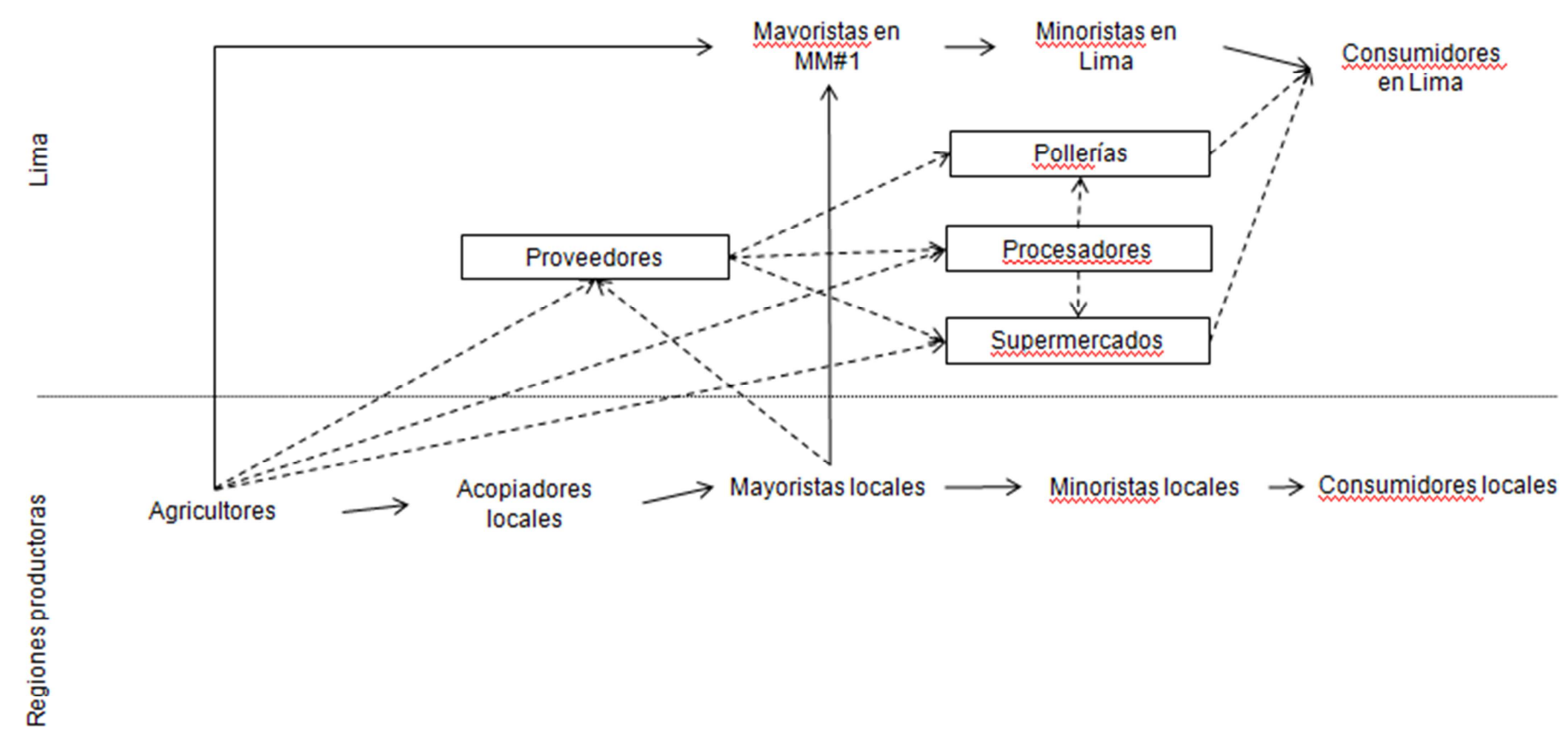

Nota: Encerrados en caja son los nuevos actores de la cadena.

Fuente: Elaborado en base de Bernet et al., 2008: 18. 
Figura 2: Funciones de los actores en la cadena productiva de la papa en Lima

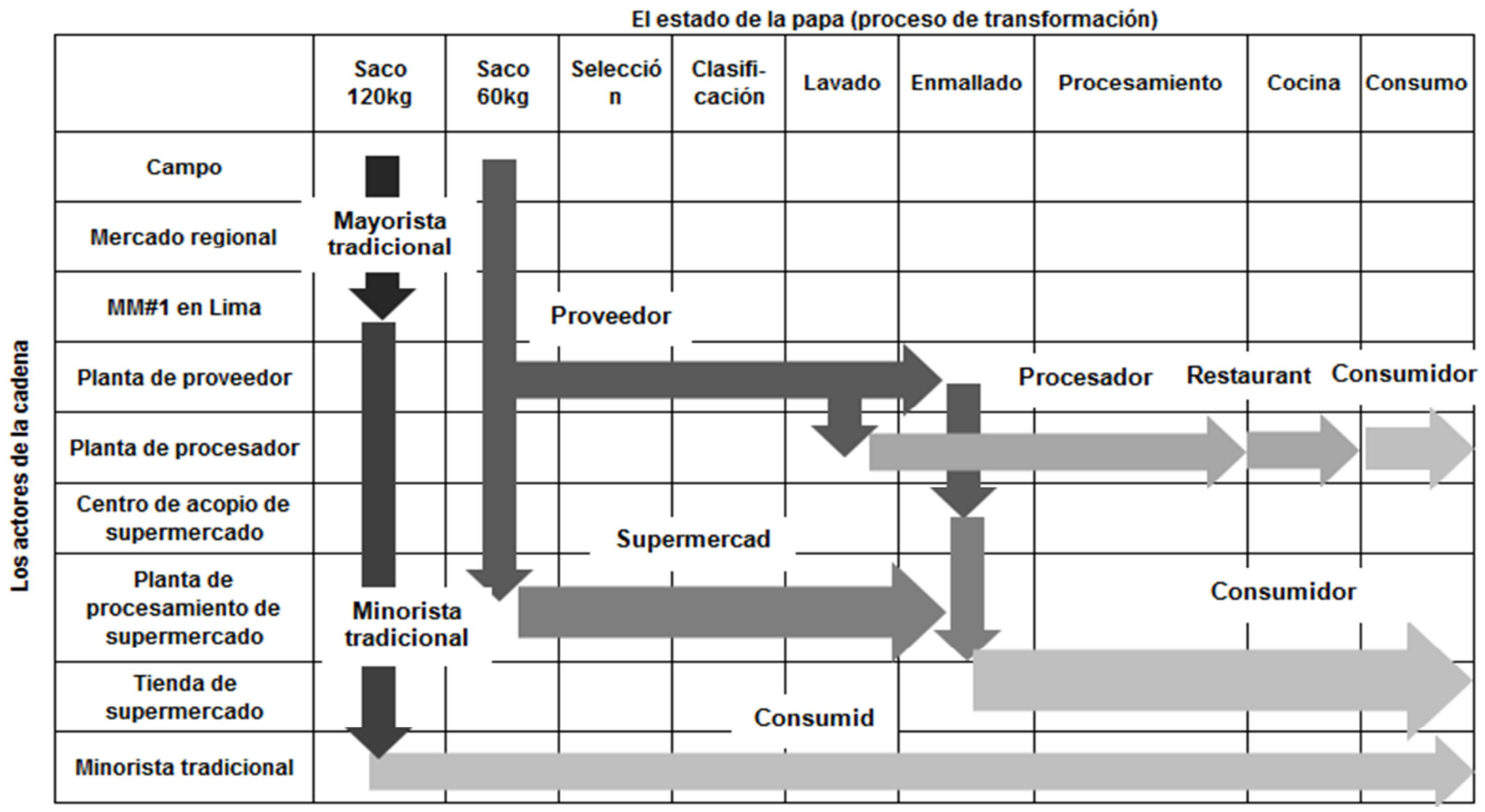

Fuente: Elaboración propia. 


\section{Resultados}

Los canales de comercialización de papa tradicionales. Entre la chacra y la ciudad, papas llegan a Lima por diferentes canales de comercialización (Fig. 1). Dentro de las canales, los mayoristas en el MM\#1 juegan un papel importante ${ }^{4}$. Ellos coordinan los envíos a la capital donde las transacciones se realizan en un mercado abierto al contado (open and spot market) sin contratos, pero basadas más en la confianza entre compradores y vendedores (Scott y Zelada, 2011).

En las zonas de producción, no hay instalaciones de recibir, lavar, seleccionar y empacar los tubérculos (Bernet et al., 2008). En lugar de eso, la selección está hecha a mano en el campo mismo, casi exclusivamente por el tamaño. Los productores llenan papas en los sacos grandes de 100-120 kg, y los despachan por camión a los mayoristas de MM\#1 en Lima.

Después de recibir papas en MM\#1, los mayoristas venden los tubérculos a sus clientes, sin abrir los sacos. Tampoco en el mercado, no hay espacios para procesar. Las papas son sucias y mezcladas con diferentes tamaños (López Benavides, 1997: $6)$. Los minoristas tradicionales compran estas papas y venden en los puestos de los 1,300 mercados municipales o en bodegas de vecindario de la ciudad (Garcia Vega, 2011). Muchas veces ellos compiten ofreciendo a sus clientes estas papas con poco valor agregado. No hay casi ninguna transformación de papa entre la chacra y los consumidores (Fig. 2).

Las papas variedades híbridas como Canchan, Perricholi, y Yungay representan más de $80 \%$ de papas que ingresan al mercado mayorista de Lima. Los comerciantes refieren a todas esas papas como "papa blanca" por su carne blanca. Generalmente llegan al mercado directamente de los campos

${ }^{4}$ Las operaciones en el Mercado Mayorista Número Uno de Lima (MM\#1) fueron trasladadas al nuevo Gran Mercado Mayorista de Lima (GMM) en Santa Anita en octubre del 2012. Porque varios comerciantes rechazaron a mudarse, el volumen del ingreso al mercado mayorista calló por $21 \%$, desde 537,767 toneladas métricas (TM) en 2011 al MM\#1 a 426,873 TM en 2013 al GMM. 
de los medianos y grandes productores (Scott, 1985; Alarcón y Ordinola, 2002: 95; CEPES, 2010). Las variedades de papas amarillas (p.ej., Tumbay y Peruanita), todas designadas como "papa amarilla" por su carne amarilla han sido vendidas durante décadas en Lima (Scott, 1985). Además, hay las variedades nativas más "exóticas" como Huayro y Huamantanga (Devaux et al., 2010: 308). Estas variedades recién empiezan de aparecer con frecuencia en los mercados urbanos, son enviados al MM\#1 en Lima a través de acopiadores y mayoristas locales en las regiones (Bernet et al., 2008: 18; Meinzen-Dick et al., 2009; Scott, 2011c).

La papa se produce en las zonas geográficas de la sierra (95\%), costa $(5 \%)$ y selva $(<1 \%)$. La sierra genera variedades blancas, amarillas y nativas y envía el $65-70 \%$ del volumen total que llega a la capital al año. En el caso de la costa, toda la producción es de papa híbrida. Las regiones de Lima e Ica despachan alrededor $30-35 \%$ de todos los envíos de papa anuales a Lima. Gracias a las variadas condiciones ecológicas que hay en el Perú, se cosecha papa fresca durante todo el año.

La procedencia de la papa que llega a los mercados en Lima va variando entre zonas de alta producción en las dos regiones (Bernet et al., 2008: 23). En la sierra, la cosecha de papa se concentra entre los meses de marzo y junio, mientras que en la costa la cosecha se concentra entre los meses de agosto y octubre $^{5}$. Como la Figure 3 muestra, la procedencia de los flujos a Lima rotan en sentido horario, empezando por el noroeste (de Huánuco y después Pasco), este (primero de Tarma, y luego de Jauja y Huancayo), sureste (Huamanga), sur (Nazca, Ica y eventualmente Cañete), y finalmente norte (Huaral y después Barranca) (Cabrera, 2012). Entonces, los mayoristas en Lima mantienen contacto con miles de productores y comerciantes en diferentes centros de producción en la sierra y costa del país en el transcurso del año. Además, dada las variables condiciones climáticas y vulnerable infraestructura vial en la sierra, los

${ }^{5}$ EI MINAG publica datos sobre el porcentaje de la siembra y cosecha en cada región en su calendario agrícola (http://www.minag.gob.pe/portal/sectoragrario/agricola/calendario-agr\%C3\%ADcola). 
cambios en la oferta de diferentes regiones y la demanda por diferentes actores, y siendo la papa un producto semiperecedero, las operaciones logísticas de organizar un flujo de papa a Lima medido y sostenido representan un desafío significativo. Estos son algunos factores por los cuales la comercialización de la papa ha sido coordinada y liderada, sino hasta dominada, por doscientos mayoristas en el MM\#1en Lima durante décadas.

Según las cifras del Ministerio de Agricultura (SHPA-MINAG), un promedio de $19 \%$ de la producción nacional de papa anual ha llegado a Lima durante los últimos diez años. Del total de papa que llega a Lima, un promedio de $74 \%$ ingresa al MM\#1 de Lima. De tal manera que de las 710,000 TM de papas que llegaron a Lima durante 2011, 538,000 TM ingresaron al MM\#1, o un promedio de 1,300 a 1,400 TM diarias. ${ }^{6}$

Los cambios de la oferta y la demanda. El volumen de los envíos de papa a Lima ha casi triplicado y diversificado en las últimas tres décadas en función del recuperación y después despegue de la producción del cultivo desde 1990 superando los 4 millones TM en el 2011 (Scott, 20011a; Fig. 4). El crecimiento de la producción del arroz también ha sido notable, pero menos alto. Entre los factores que contribuyeron al aumento de la producción de papa fueron la estabilidad de la macroeconomía, la recuperación del crédito para la agricultura, el mejoramiento de seguridad en el campo, el avance de la infraestructura como carreteras e irrigación, la difusión de tecnologías mejoradas, años sin un problema climático (como una sequía) o fitosanitario mayor, y el crecimiento en la demanda (CEPES, 2010, p. 7; Scott, 2011a).

\footnotetext{
${ }^{6}$ No hay cifras sobre la cantidad de papas que llegan directamente a los cinco mercados mayoristas satélites que han sido organizados en diferentes partes de la capital desde 1990, ni a las fábricas de hojuelas, o a las pequeñas plantas de papa pelada y cortada para los pollerías (Scott y Ocampo, 2013).
} 
Figura 3. Ingreso mensual de papa blanca al Mercado Mayorista \#1 de Lima, 2011

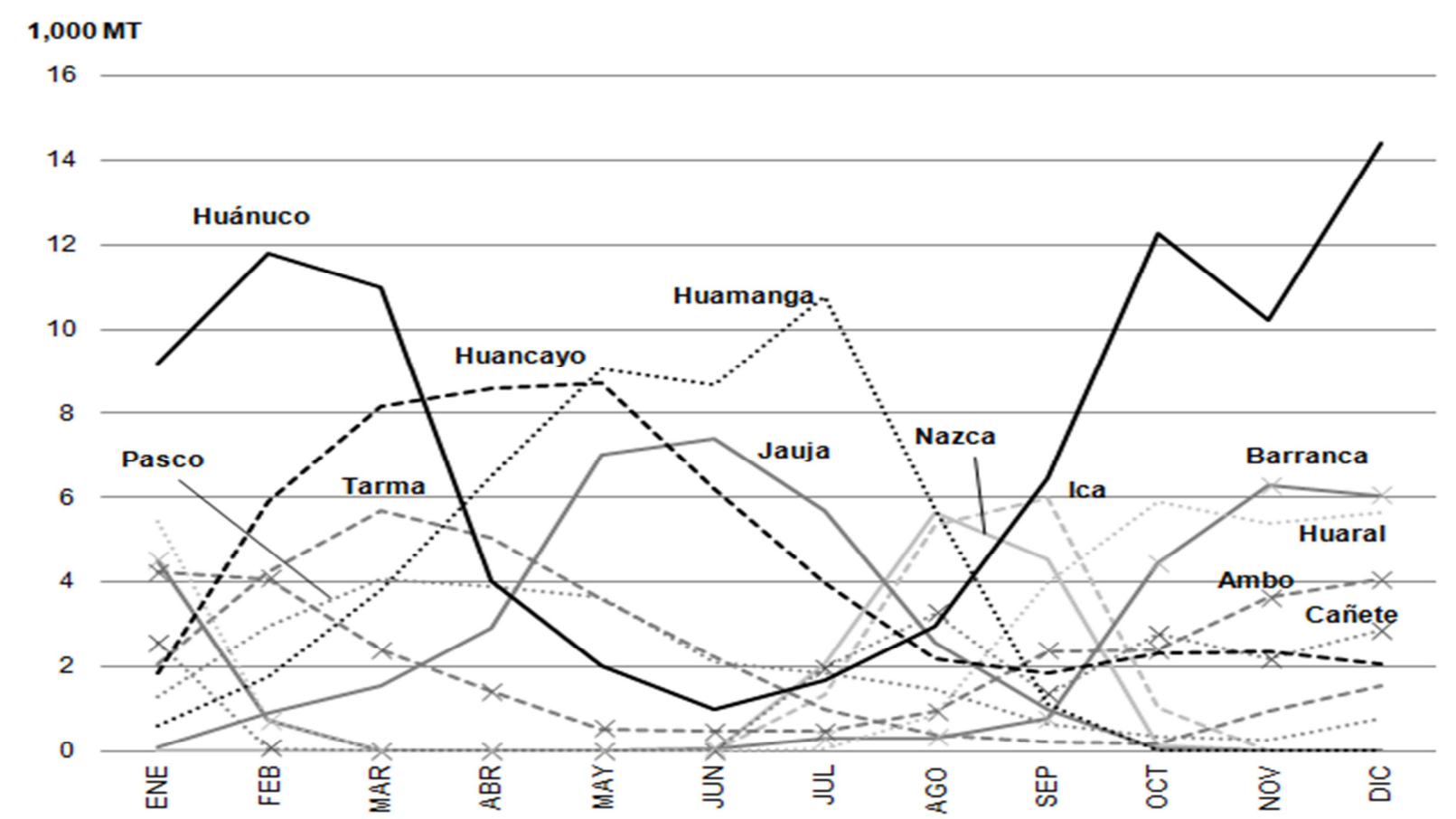

Fuente: Elaborado en base de los datos de SISAP-MINAG. 
Figura 4. Producción y consumo de papa y arroz en el Perú, 1961-2011

1,000 TM

kg/año/persona

4,500

4,000

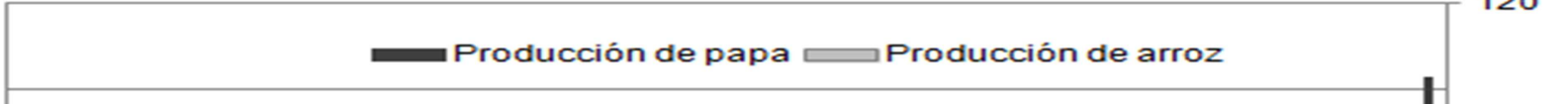

3,500

3,000

2,500

2,000

$-1,500$

1,000

500

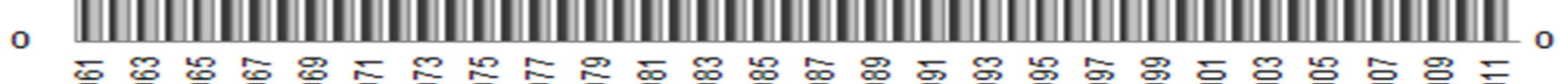

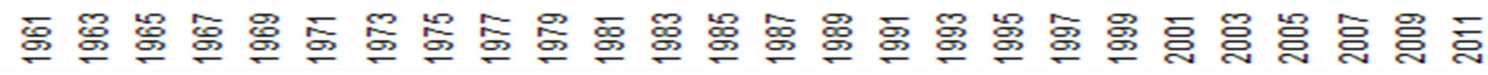

Fuente: Elaborado por el autor con los datos de FAOSTAT. 
La papa juega múltiples roles en la dieta de los peruanos: alimento básico; complemento; snack; bocadito. Por esa versatilidad y con la recuperación de la economía después de la crisis de los fines de los 80 , la demanda de papa recuperó en una forma espectacular desde 1990. El hecho de que el consumo per cápita de papa siguió creciendo con el aumento en los ingresos reales (de Althaus, 2007; Jaramillo y SilvaJáuregui eds., 2007; Webb, 2013) se explica en parte en la medida que las formas de consumo de papa han diversificadas para incluir diversos tipos de variedades nativas y diversos usos para las papas blancas hibridas (Ordinola et al., 2007a, 2007b, 2009, 2011; Scott, 2011c; Escobal y Cavero, 2012; Horton y Samanamud, 2013; Scott y Ocampo, 2013).

Uno de los ejemplos es el consumo de papa en restaurantes. Un estudio de 400 locales en Lima muestra que la papa es uno de los insumos más importantes junto con el pollo y el arroz (Proexpansión, 2011: 105-108). Se estima que 35 mil restaurantes en Lima consumieron alrededor de 69,000 TM de papa en 2010, las cuales representan el $13 \%$ de papa que ingresó a la capital ese año. El mismo estudio estimó que el consumo de papa por los restaurantes en la capital llegará alrededor de 100,000 TM en el 2013 (Proexpansión, 2011: 114). A excepción de la importación anual de unos 23,000 TM, o su equivalente en forma fresca, de papa pre-frita y congelada (Scott y Ocampo, 2013), toda la papa para el consumo humano en el Perú es de producción nacional.

En resumen, el consumo de papa se ha incrementado por el aumento en los ingresos reales, la creciente popularidad de la gastronomía peruana incluyendo la cocina Novoandina, la preferencia del público masivo por comer pollo a la brasa como su plato favorito, la marcada tendencia por parte de los consumidores de buscar más productos y platos diferentes que incluyen papa, y los precios relativamente cómodos y menos fluctuantes que en décadas anteriores (Ordinola et al., 2009, 2011; Bendezu et al., 2010; Scott, 2011b; Escobal y Cavero, 2012; Webb, 2013).

Como consecuencia de esas variadas tendencias en la oferta y 
la demanda, la venta de papa en los supermercados también está creciendo con la expansión de éstos. Según la Encuesta Nacional de Hogares (ENAHO) realizada el año 2009, la población compra el 3\% de papa de supermercados, la cual equivale 24,000 TM por año (Proexpansión, 2011: 119). Según un informante clave contactado para este estudio, solamente una de las cadenas de supermercados comercializaba esta cantidad de papa en 2013. Más aun, las cadenas de supermercados mismas han promovido el mayor y más diversificado consumo de papa en el país por las innovaciones que ellas han introducidas (Alarcón y Ordinola, 2002; Ordinola et al., 2009, 2011). Estas incluyen los nuevos productos de papa puesta en venta en sus estantes (p.ej., hojuelas de diferentes tipos, papas procesadas tradicionales pero de mejor calidad, etc.); el auspicio de eventos públicos festejando el consumo de papa; las promociones y propaganda sobre la papa en venta en sus tiendas; y el manejo de la papa fresca en los canales alternativos desarrollados por ellas.

Los canales de compras de los supermercados. Hasta la década de los noventa cuando había menos papa, menos demanda, y menos tiendas, los supermercados en Lima compraban papa en el MM\#1. Sin embargo, hoy en día dicho mercado no es el lugar de abastecimiento principal de papa para ninguna de las tres cadenas de supermercados entrevistadas para este estudio. Ellos se abastecen de papa principalmente desde los proveedores especializados. Solamente cuando sus proveedores no pueden cumplir con sus pedidos, ellos acuden a los mayoristas del MM\#1. Es decir que los supermercados han desarrollado un canal alternativo de abastecimiento independiente, aunque no necesariamente de sus mayoristas.

La estrategia que los supermercados adoptaron para abastecerse de volúmenes programados de alta calidad era desarrollar canales de comercialización cerrados y coordinados (Lau, 2008). Es decir, en lugar de realizar las compras de día en día y al contado en el mercado mayorista, los supermercados establecen relaciones comerciales fijas y nuevos procedimientos de aprovisionamiento para permitir un mayor 
intercambio de información sobre las transacciones. Son los procedimientos que no estuvieron factibles décadas atrás cuando no existían teléfonos celulares ni internet (Scott, 1985; de Althaus, 2007; Webb, 2013). Los supermercados adoptan esta estrategia de compra cuando no se puede encontrar en los mercados tradicionales productos con características específicas y/o tener mayor control sobre calidad, cantidad, flujo y seguridad de los productos (Humphery, 2007, p. 442).

¿Por qué los canales tradicionales no pueden satisfacer la demanda de los supermercados? Eso tiene que ver en parte con las características del mercado mayorista como un mercado abierto al contado (open and spot market). Los mercados que trabajan al contado no pueden intermediar muy bien la oferta y la demanda de los productos diferenciados por el problema del desajuste entre la oferta y la demanda. MacDonald explica este problema con un ejemplo de producción de productos agrícolas (MacDonald et al., 2004: 24-25). Para producir un producto diferenciado de alta calidad incluyendo orgánica y con nutriciones especiales, un agricultor tiene que invertir más en el manejo del producto durante su ciclo vegetativo con fertilizantes, pesticidas y control de agua, y después de la cosecha con manejos y empaques especiales (Bernet et al., 2002). Si el agricultor vende un producto diferenciado de alta calidad en un mercado abierto al contado, él no puede estar seguro si habrá un comprador quien esté dispuesto a pagar un precio alto por este producto. Si nadie paga un precio alto, el agricultor tendrá que vender su producto con el precio de uno de calidad media y así no podrá recuperar su inversión. Éste es el problema de "hold-up". Cuando existe este problema, es más probable que el agricultor produzca un producto de calidad media. Por esta razón, el mercado abierto al contado no puede intermediar muy bien la oferta y la demanda de los productos diferenciados de alta calidad.

Otra razón para que el canal tradicional no pueda satisfacer la demanda de los supermercados tiene que ver con los mismos mayoristas. Además de alta calidad en los productos, las cadenas de supermercados también requieren una oferta de cantidad estable y programada para abastecer sus crecientes 
números de tiendas. Para lograr esto, sus proveedores tienen que comprometerse haciendo las inversiones necesarias y aceptando después un pago deferido por cada transacción. Muchos mayoristas no tienen y/o no están dispuestos a arriesgar los recursos financieros para hacer este tipo de negocio. Ellos prefieren rotar su capital más rápido, maximizar los volúmenes, evitar los riesgos del cambio de precios, y no procesar papas entre otras razones por falta de espacio dentro del MM\#1 (Scott y Zelada, 2011).

Además de los precios de papa que los mayoristas de MM\#1 ofrecen, los compradores tienen que asumir los costos la carga y descarga, transporte hasta y desde el mercado, tiempo de viaje y búsqueda de vendedores, pérdida de peso, etc. También, se relacionan con la calidad y la presentación de los productos. Mientras el mercado mayorista ofrece papas en sacos grandes de $100-120 \mathrm{~kg}$ con calidad heterogénea y tamaños variados, los supermercados demandan papas que puedan colocar en los estantes de sus tiendas. Es decir que las papas tienen que estar seleccionadas, lavadas, clasificadas, enmalladas y listas para vender al consumidor.

En esas circunstancias, los supermercados han optado por diferentes prácticas para organizar canales de compra cerrados y coordinados, (Reardon et al., 2003; Humphrey, 2007; Reardon y Timmer, 2007). Una es el abastecimiento con un centro de distribución (punto de acopio) centralizado. Cuando crece el número de tiendas de la cadena de supermercados, ellos dejan de abastecerse tienda por tienda y empiezan a centralizar sus compras para todas las tiendas, aprovechando las economías de escala. Otra práctica es el uso de proveedores especializados 0 proveedores preferidos que asumen los trabajos de preparación del producto para la venta al por menor.

Ambas prácticas involucran una serie de procedimientos distintos de los del canal tradicional incluyendo: i) una programación de compras con mayor anticipación, p. ej., los supermercados programa semanalmente la cantidad de papas que reciben y venden; ii) transacciones formales: todas las transacciones que realizan los supermercados tienen que ser 
de empresas formales y con los documentos tributarios requeridos (facturas); iii) un momento y forma de pago distinto, p.ej., los supermercados pagan entre una semana a un mes después de entrega de la papa a través de giros bancarios; y iv) otros servicios y requerimientos, p.ej., la entrega de papas debe ser en jabas del supermercado y en los horarios especificados; los camiones que transportan los productos tienen que ser cubiertos y no pueden transportar productos tóxicos, etc.

Formación de los proveedores especializados. LoS proveedores especializados de papa para las cadenas de supermercados incluyen un grupo selectivo de mayoristas de papa del MM\#1; algunos comerciantes de papa en provincia, quienes habilitan la producción proporcionando créditos en forma de insumos y efectivo; y algunos productores grandes mismos, quienes venden no solamente su propia producción, sino también acopian de otros agricultores en la zona. Estos proveedores están "especializados" en el sentido que trabajan con un solo rubro de productos tales como tubérculos, incluyendo papa, camote, olluco, etc.; o un producto como papa; o inclusive con un tipo de cultivo específico como papa blanca o papa amarilla.

Además, los supermercados compran solamente a los proveedores especializados "preferidos" quienes generalmente están registrados en una lista de proveedores manejado por cada cadena. Las cadenas trabajan con su lista de proveedores preferidos para disminuir los costos de transacción relacionados con buscar un proveedor de día en día o de semana en semana. Algunos de estos proveedores están trabajando con la misma cadena de supermercados casi 20 años. Para estar incluido en la lista, el potencial proveedor tiene que estar registrados con la superintendencia tributaria como una empresa formal; emitir documentos formales; tener capacidad de abastecer la escala mínima tal como más de 10 TM a la semana, etc. En algunos casos los comerciantes que aspiran de ser proveedores preferidos tienen que asistir a charlas de capacitación y solamente después de algunas pruebas pueden calificarse de estar en la lista. 
Desde el punto de vista de los proveedores, una vez de estar en la lista pueden asegurar sus compradores establecidos en provincia la compra y despacho de cierto volumen de papa de semana en semana. Así, los proveedores pueden programar sus operaciones de acopio, intentar a asegurar sus abastecedores los mejores precios vigentes en el momento de la venta para evitar el "hold-up", y hacer las inversiones necesarias en infraestructura, el contrato de personal y la disposición de capital operativo para satisfacer la demanda de los supermercados.

Un supermercado en general tiene varios proveedores para cada cultivo. En el caso de la papa hay proveedores diferentes para papa blanca y amarilla, porque la zona de producción es diferente. En el caso de las papas nativas exóticas, las cuales se venden solamente en la época de cosecha, existen otros proveedores.

\section{La estrecha coordinación entre supermercados y} proveedores. Los proveedores en la lista de los supermercados reciben información sobre la papa con una ficha técnica. Esta información detalle los estándares que debe tener la papa para que los supermercados la acepten. Posteriormente, los proveedores reciben los pedidos de supermercados con anticipación. En algunos casos, los supermercados avisan a los proveedores con dos o tres días de anticipación. En otros casos, los supermercados hacen pedidos el día viernes para la semana siguiente. Los proveedores tienen que abastecer papas en un día especificado por los supermercados 0 en el transcurso de la semana. Para las ofertas de las tiendas de los supermercados, los proveedores reciben pedidos con mayor anticipación.

Cuando los supermercados hacen los pedidos, ellos también fijan los precios teniendo en cuenta los precios del MM\#1. En caso de hacer pedidos por una semana, el precio es fijo durante de la semana. Solamente cuando hay cambios significativos del precio del mercado mayorista, los supermercados y sus proveedores negocian un ajuste de precios. Respecto a los precios y volúmenes de compraventa, solamente hay acuerdos 
verbales.

El trabajo de los proveedores es comprar papas, procesarlas y entregarlas a los centros de acopio de las cadenas de supermercados. Los proveedores entrevistados indicaron que compran la mayoría de las papas de los productores a través de sus compradores itinerantes y de comerciantes con base en las diferentes zonas de producción. Los compradores itinerantes son los agentes de los proveedores especializados. Ellos se trasladan entre las zonas de producción en la sierra y la costa monitoreando la situación de la producción de papas y siguiendo las cosechas. Algunos compradores trabajan para un proveedor por todo el año, mientras otros trabajan solamente en algunas épocas cuando hay un pedido de proveedores en una zona específica. Por medio de sus redes de compradores y comerciantes, los proveedores aseguran los volúmenes y calidad de abastecimiento requerido.

Las papas compradas en provincia llegan por camión a los locales de los proveedores en la capital. Estos están ubicados cerca del MM\#1 en el centro de ciudad o en distritos lejanos cerca donde se ubican los centros de acopio y distribución de las cadenas de supermercados. Cuando las papas llegan, los proveedores inspeccionan la mercadería con la muestra. En el caso de que las papas pasan la inspección, los proveedores las reciben, descargan y pesan. Al mismo tiempo, pagan a los productores o comerciantes a través de giro bancario o en efectivo.

Posteriormente sigue el proceso de seleccionar, clasificar, lavar y enmallar. La selección es para eliminar papas dañadas, podridas o verdeadas. Los proveedores clasifican la papa en tres o cuatro categorías según su calibre siguiendo las fichas técnicas. Un proveedor entrevistado por este estudio clasifica en las cuatro categorías de tubérculos: súper-grande, grande, mediana y pequeña. Las papas súper-grandes son para los procesadores de papa pelada y cortada para las pollerías. El resto es para supermercados. Las grandes son para las tiendas en las zonas de pobladores con mayor poder adquisitivo. Las pequeñas se venden al peso sin lavar en las temporadas de 
ofertas. Después las lavan con agua y las enmallan, separando las papas con daños o con heridas que solamente se notan después de la lavada. Al final se ponen etiquetas que identifican el proveedor y la fecha de entrega (día de la semana). Luego se colocan las papas en las jabas de plástico alquiladas de los supermercados. Los proveedores entregan las papas a los centros de acopios de los supermercados en las horas designadas. Los tubérculos que no se pueden vender a los supermercados se venden en otro lugar, tal como en el MM\#1.

En el centro de distribución de los supermercados, una vez que el personal del supermercado inspecciona la mercadería y la recibe, emiten una liquidación de compra. Es un comprobante de la recepción de la mercadería. Con este documento, los proveedores preparan facturas y las entregan a los supermercados para recibir su pago diferido después.

La integración del procesamiento por los propios supermercados. En lugar de comprar papas procesadas de proveedores especializados, algunas cadenas empezaron a comprar y procesar papas en sus instalaciones con su propio personal. Una ventaja de este procedimiento es poder realizar una "compra de campo," cortando los canales de comercialización y ahorrando los márgenes que antes pagaban a los proveedores, quienes las procesan. Además, la práctica de "compra de campo" puede mejorar la imagen del producto en calidad y frescura; y por la cuestión de la trazabilidad del producto vendido (Lau, 2008).

Para procesar papas los supermercados alquilan un local o usan un espacio dentro del centro de distribución. Adicionalmente invierten para instalar la línea de clasificación y lavado. Los supermercados comentaron que ellos procesan solamente papas Canchán y Tumbay, las cuales son las principales variedades que se venden en los supermercados y que ocupan entre 70 a $90 \%$ del total de venta de papas. Solamente estas dos variedades tienen el volumen de ventas suficientes para justificar la inversión.

Cuando los supermercados procesan la papa, ellos compran de medianos y grandes "productores" quienes son habilitadores al 
mismo tiempo. Cuando los "productores" preparan las papas para supermercados, la selección es más estricta que cuando las papas se van al mercado mayorista. Los "productores" seleccionan papas en buenas condiciones y con el tamaño mayor que el especificado por el supermercado. No las clasifican por tamaños. En lugar de usar sacos de 100-120 kg, los proveedores usan sacos de $50-60 \mathrm{~kg}$, con los cuales las papas se dañan menos y se conservan mejor. Las etapas del procesamiento de papa son básicamente las mismas que tienen los proveedores especializados.

\section{Conclusión}

Con el crecimiento económico, la demanda de los alimentos está aumentando y diversificándose. Con un mayor poder adquisitivo, los consumidores demandan no solamente más hortalizas de diferentes tipos, sino también en las diferentes formas finales dependiendo de sus gustos y preferencias particulares. Además, ellos quieren comprar un conjunto de productos de buena calidad en cualquier época del año. Parte de la estrategia de expansión de los supermercados es que cada vez más pobladores compran esos productos en sus tiendas ofreciéndoles frutas y verduras de alta calidad. Se estima que el número de tiendas de los supermercados se triplicará en corto plazo afuera de Lima y se duplicará en mediano plazo a nivel nacional.

Mientras la demanda de alimentos está cambiando rápidamente, algunos actores en la comercialización de productos agrícolas están demorando en adaptarse a los cambios. En el caso de la papa, los productores, acopiadores y mayoristas tradicionales solamente trasladan los tubérculos de la zona de producción a la ciudad sin ninguna transformación física. Entonces, cuando los minoristas tradicionales colocan las papas a la venta a consumidores directos, muchas veces están sucias y presentan diferentes calidades y calibres. Son los mismos consumidores quienes tienen que seleccionar las papas de mejor calidad para su posterior lavado y cocción. 
Por su parte, los supermercados ofrecen papas seleccionadas, clasificadas, lavadas, enmalladas y listas para que los consumidores las puedan llevar. Asimismo los supermercados ofrecen estas papas de manera continua y estable para que sus clientes puedan encontrarlas en cualquier momento. Para lograr esto, los supermercados se abastecen no del mercado mayorista, sino de unos proveedores especializados a través de los canales cerrados y coordinados. Como muestra Figura 2, los supermercados y otros actores nuevos en la cadena productiva agregan valores a la papa. Además, existen otras oportunidades para los productores e intermediarios locales de transformar papas cosechadas en los productos que los consumidores prefieren. Para realizar esto, tienen que formar canales cerrados y coordinados junto con los otros actores quienes están más cerca a los consumidores.

Al mismo tiempo, va a ser interesante observar como la venta de papa fresca al por mayor y menor evoluciona en los años que vienen. ¿Empezarán los mayoristas en el nuevo $\mathrm{GMM}^{7}$ a seleccionar y vender las papas en sacos de $50 \mathrm{~kg}$ como se ha propuesto (Hibon y Soltau, 2008)? ¿Qué iniciativas tomarán los minoristas tradicionales en el manejo de las hortalizas para mantenerse competitivos? Las tendencias indican que el mercado de papa en Lima se está segmentando y los actores más innovadores son aquellos que serán más competitivos en los años que vienen. ¿Qué otras innovaciones podrían introducir los supermercados para ganar un porcentaje más alto de las ventas de papa y otras hortalizas frescas en el Perú? ¿Qué implicancias hay de estos cambios para los pequeños productores? ¿Ellos tendrán más posibilidades de integrarse con los canales alternativos de los supermercados con su expansión en las regiones? Estas son algunas de las preguntas que se quedan para contestar en futuros estudios.

\footnotetext{
${ }^{7}$ En el nuevo GMM, aunque hay planes de construir espacios para seleccionar, lavar y empaquetar hortalizas dentro del mercado, a julio del 2013 las instalaciones están aún por culminar y las operaciones parecen seguir como en el MM\#1.
} 


\section{Agradecimientos}

Este artículo es producto del proyecto de investigación "Los cambios estructurales en la comercialización de productos agrícolas en el Perú" financiado por IDE-JETRO entre 2012 y 2013. Los autores agradecen IDE-JETRO y al Centro Peruano de Estudios Sociales (CEPES) por su apoyo al proyecto.

\section{Referencias}

Alarcón, J. 1994. Comercialización de papa para consumo: el caso del eje Valle del Mantaro - Lima Metropolitana. En Escobal, J. (ed.). Comercialización agrícola en el Perú. GRADE; AID, Lima.

Alarcón, J.; Ordinola, M. E. 2002. Mercado de productos agropecuarios: Teoría y aplicaciones al caso peruano. CARE, UNALM, PRISMA, Lima.

Bendezu, E.M.; Hinastroza, J.J.; Idrogo, J.A. 2010. Plan estratégico para el sector avícola en el Departamento de Lima. Tesis de Maestría. CENTRUM Católica, Graduate Business School, Pontificia Universidad Católica del Perú, Lima.

Bernet, T.; Delgado, O.; Sevilla, M. 2008. Centros de acopio de papa: factibilidad de promover e implementar este concepto en la sierra peruana. CAPAC Perú, Lima.

Bernet, T.; Lara, M.; Urday, P.; Deveaux, A. 2002. El reto de vincular a los pequeños productores de papa con la agroindustria. Revista Latinoamericana de la Papa, 13(1):1-23.

Cabrera, A.M. 2012. La cadena productiva de la papa en el Perú. Presentación preparada para el XXV Congreso de la Asociación Latinoamericana de la papa, 17-20 de septiembre en Uberlândia, Minas Gerais, Brasil.

CEPES. 2010. Desarrollo de la Metodología de encuestas de márgenes y canales de comercio y su implementación en siete cadenas productivas agropecuarias. Producto 14 Informe de la cadena de PAPA, Programa de servicios de Apoyo para Acceder a los Mercados Rurales (PROSAAMER) para la Oficina de Estudios Económicos y Estadísticos (OEEE) del Ministerio de Agricultura 
(MINAG). Centro Peruano de Estudios Sociales (CEPES), Lima.

de Althaus, J. 2007. La revolución capitalista en el Perú. Fondo de Cultura Económica, Lima. 333p.

Devaux, A.; Ordinola, M.; Hibon, A.; Flores, R. 2010. El sector papa en la región andina: Diagnóstico y elementos para una visión estratégica (Bolivia, Ecuador y Perú). Centro Internacional de Papa (CIP), Lima.385p.

Escobal, J. (ed.).1994.Comercialización agrícola en el Perú. GRADE,USAID, Lima. 329p.

Escobal, J.A. 2000. Competitividad y eficiencia en la comercialización mayorista en el Perú. Documento presentado al taller "Concentración de los segmentos de transformación y mercadeo del sistema agroalimentaria y sus efectos sobre los pobres rurales," 27-28 Noviembre, Santiago de Chile. Procesado. 11p.

Escobal, J.A.; Cavero, D. 2012. Transaction costs, institutional arrangements and inequality outcomes: Potato marketing by small producers in rural Peru. World Development, 40 (2): 329-341.

FAOSTAT (http://faostat.fao.org/), varios años, consultado enero a diciembre, 2012.

Garcia Vega, E. 2011. Una aproximación al retail moderno. Universidad del Pacífico, Lima. 197p.

Hibon, A.; Soltau, L. 2008. Promoviendo un envase seguro y eficiente para la comercialización de tubérculos en el Gran Mercado Mayorista. Procesado. A Tiempo, Lima.

Horton, D.; Samanamud, K. 2013. Peru's native potato revolution. Papa Andina Innovation Brief 2. International PotatoCenter (CIP), Lima, Peru.

Humphrey, J. 2007. The supermarket revolution in developing countries: Tidal wave or tough competitive struggle. Journal of Economic Geography 7: 433-450.

Jaramillo, C.F.; Silva-Jáuregui, C.S. (eds.). 2011. Perú en umbral de una nueva era. Lecciones y desafíos para consolidar el crecimiento económico y un desarrollo más incluyente. Notas de política. Volumen 
1. Banco Mundial, Washington, D. C. 162p.

Lau, M. 2008. Papa pre-frita congeladas, lavadas, seleccionadas y empacadas: La experiencia de autoservicios WONG. Presentación en PowerPoint al Primer Congreso Nacional de la Papa. Huancayo. (http://www.minag.gob.pe/portal/especiales/congreso-de-la-papa).

López Benavides, G. 1997. "Situación actual del mercado de papa fresca y perspectivas mercadológicas en la Gran Lima." Convenio ADEX-AID MSP, Lima.

MacDonald, J.; J. Perry; M. Ahearn; D. Banker; W.Chambers; C. Dimitri; N. Key; K. Nelson; L.Southard. 2004. Contracts, Markets, and Prices: Organizing the Production and Use of Agricultural Commodities. Agricultural Economic Report No. 837. United States Department of Agriculture, Washington, D. (http://www.ers.usda.gov/media/284610/aer837_1_.pdf)

Meinzen-Dick, R.; Deveaux, A.; Antezana, I. 2009. Underground assets: Potato diversity to improve the livelihoods of the poor. International Journal of Agricultural Sustainability, 7(4):235-248.

Ordinola, M.; Bernet, T.; Manrique, K.; Fonseca, C. 2007a. Promoviendo innovaciones con los actores de la cadena y revalorizar la biodiversidad de la papa. El desarrollo y aplicación del enfoque participativo de cadenas productivas (EPCP) en el Perú. Centro Internacional de la Papa (CIP), Lima. 55p.

Ordinola, M.; Bernet, T.; Manrique, K. 2007b. T'ikapapa: Vinculando consumidores urbanos y pequeños productores andinos con la biodiversidad de la papa. Centro Internacional de la Papa (CIP), Lima. $55 p$.

Ordinola, M.; Devaux, A.; Manrique, K.; Fonseca, C.; Thomann, A. 2009. Generando innovaciones para el desarrollo competitivo de la papa en el Perú. Centro Internacional de la Papa (CIP), Lima. 64p.

Ordinola, M.; Devaux, A.; Manrique, K.; Fonseca, C.; Thomann, A. 2011. Strengthening competitiveness of the potato market chain: An experience in Peru. En Devaux, A., Ordinola, M. y Horton, D. (eds.). Innovation for Development: The Papa Andina Experience. Centro Internacional de la Papa (CIP), Lima. 431p.

Proexpansión. 2011. Cambios del sector papa en el Perú en la última 
década: Los aportes del proyecto Innovación y Competitividad de la Papa (INCOPA). Centro Internacional de la Papa (CIP), Lima. 179p.

Reardon, T.; Berdegué, J.A. 2002. The rapid rise of supermarkets in Latin America: Challenges and opportunities for development. Development Policy Review, 20(4): 371-388.

Reardon, T.; Timmer, C.P.; Barrett, C.B.; Berdegué, J.. 2003. The rise of supermarkets in Africa, Asia, and Latin America. American Journal of Agricultural Economics, 85 (5): 1140-1146.

Reardon, T.; Timmer, C. P. 2007. Transformation of markets for agricultural output in developing countries since 1950: how has thinking changed? pp. 2807-2855. En Evenson, R.; Pingali, P. (eds.). Handbook of Agricultural Economics, Vol. 3, North Holland, Amsterdam, $846 p$.

Scott, G. 1985. Mercados, mitos e intermediarios. Un estudio de la comercialización de la papa en la zona central del Perú. Centro de Investigación de la Universidad del Pacífico (CIUP), Lima. 308p.

Scott, G. 2011a. Growth rates for potatoes in Latin America in comparative perspective: 1961 -

2007. American Journal of Potato Research, 88(2), 143-152.

Scott, G. 2011b. Tendencias cruzadas: El consumo y utilización de la papa en América Latina entre 1961 y 2007 y sus implicancias para la industria. Revista Latinoamericana de la Papa, 16 (1):1-38.

Scott, G. 2011c. Plants, people, and the conservation of biodiversity of potatoes in Peru. Natureza \& Conservação, 9(1), 1-18.

Scott, G.; Ocampo, J.P. 2013. Costos efectivos, tasas de cambio y competitividad: El caso de los procesadores de papa en Lima. Custos e @gronegócio, 9(2), 2-26.

Scott, G.; Zelada, F. 2011. Benchmarking local potato processing in developing countries: The case of French fries in Lima, Peru. Potato Research, 54 (1): 29-44.

SHPA (Series Históricas de Producción Agrícola) - MINAG (Ministerio de Agricultura). (http://frenteweb.minag.gob.pe/sisca/), varios años, consultado enero a diciembre 2012. 
SISAP (Sistema de Abastecimientos y Precios) - MINAG (Ministerio de Agricultura). (http://sistemas.minag.gob.pe/sisap/portal/), varios años, consultado enero a diciembre 2012.

Tollens, E. 1997. Wholesale markets in African cities: Diagnosis, role, advantages, and elements for further study and development. FAO, Rome.

(https://www.msu.edu/course/aec/841/Discussion/Tollens_Wholesale_ Mkts_Afria_AC0597E-1.pdf)

USDA. 2012. Peru: Retail Foods. Global Agricultural Information Network report. United States Department of Agriculture, Foregin Agricultural Service.

Webb, R. 2013. Conexión y despliegue rural. Instituto del Perú, Universidad de San Martín de Porres, Lima. 272p. 